\title{
Psicologia brasileira: uma análise de seu desenvolvimento*
}

\section{Brazilian Psychology: an Analysis of its Development}

La psicología de Brasil: un análisis de su desarrollo

Enviado: 10 de noviembre de 2014 | Revisado: 5 de marzo de 2015 | Aceptado: 10 de junio de 2015

\author{
JAIRO EDUARDO BORGES-ANDRADE ** \\ Universidade de Brasília \\ Antonio Virgílio Bittencourt Bastos \\ Universidade Federal da Bahia \\ Maria Amalia Pie Abib Andery \\ Pontifícia Universidade Católica de São Paulo \\ RAQUEL SOUZA LOBO GUZzo \\ Pontifícia Universidade Católica de Campinas \\ Zeidi Araujo Trindade \\ Universidade Federal do Espírito Santo
}

doi:10.11144/Javeriana.upsy14-3.pbua

Para citar este artículo: Borges-Andrade, J. E., Bastos, A. V. B., Andery, M. A. P. A., Guzzo, R. S. L, \& Trindade, Z. A. (2015). Psicologia brasileira: uma análise de seu desenvolvimento. Universitas Psychologica, 14(3), 865-880. http://dx.doi. org/10.11144/Javeriana.upsy14-3.pbua

* Artículo de reflexión.

*** Autor de correspondencia: jairo.borges@gmail.com
RESUMO

O presente trabalho apresenta uma análise crítica sobre o desenvolvimento do campo profissional da Psicologia no Brasil e da formação de seus profissionais nos níveis da Graduação e Pós-Graduação. Alguns estudos anteriores são utilizados para descrever aquele campo e esta formação e foram considerados para uma caracterização post facto. Este ensaio finaliza com a apresentação de subsídios para políticas que visem a formação e profissionalização de profissionais no país atendendo principais e urgentes demandas sociais e educacionais.

Palavras chave

Formação em Psicologia; exercício profissional; políticas educacionais

\section{A B S T R A C T}

This paper presents a critical analysis of the development of the professional field of Psychology in Brazil and of the training of its professionals, at the undergraduate and graduate levels. Some previous studies are used for describing that field and this training. They have been taken in to account, in order to provide a post facto characterization. This essay finishes providing contributions for training and professional policies that may serve the Country's major and urgent social and educational demands.

Keywords

training in Psychology; professional practice; educational policies

\section{RES UMEN}

Este artículo presenta un análisis crítico del desarrollo del campo profesional de la psicología en Brasil y de la formación de sus profesionales a nivel de pregrado y postgrado. Se utilizan algunos estudios previos para describir el campo y la formación. Estos estudios permiten una caracterización post facto. Este ensayo finaliza proponiendo políticas para la formación y la profesión que sirvan para atender las urgentes demandas sociales y educativas del país. Palabras clave

formación en Psicología; práctica professional; políticas educativas 
Jairo Eduardo Borges-Andrade, Antonio Virgílio Bittencourt Bastos, Maria Amalia Pie Abib Andery, Raquel Souza lobo Guzzo, Zeidi Araujo Trindade

\section{Introdução}

A Psicologia foi regulamentada no Brasil, como profissão, em 27 de agosto de 1962. Essa regulamentação foi feita por meio de uma Lei que definiu atividades de natureza privativa, de quem exerce a profissão, relativas a diagnóstico e intervenção que utilizem métodos e técnicas psicológicas. Essa natureza privativa chegou a ser vetada pelo Presidente da República à época, mas depois foi mantida pelo Congresso Nacional. Não são todas as profissões regulamentadas, no Brasil, que têm definições de atividades privativas. A mencionada Lei também dispôs sobre os cursos que levariam à formação necessária, quando foram mencionadas as aplicações em educação, clínica e trabalho. Essas normas foram criadas, para organizar a profissão e o seu ensino, depois que já existiam cursos que formavam pessoas e profissionais que desenvolviam plenamente seu trabalho. A história da Psicologia brasileira, no entanto, começou a ser construída no início do século XIX, por profissionais médicos e também por educadores (Baptista, 2010; Soares, 2010), muito antes dessa Lei que definiu elementos fundamentais da formação e exercício profissionais.

Há evidências de que o ensino de Psicologia começou a ser regulamentado muito antes que a profissão, por meio de legislação nacional publicada entre a última década do século XIX e a primeira metade do século XX, voltada a faculdades de medicina e filosofia (Soares, 2010). O primeiro curso de graduação em Psicologia foi estabelecido no Brasil na década de 1950 e o primeiro mestrado em Psicologia foi criado em meados da década de 1960. O marco regulatório do currículo mínimo e a duração dos cursos de graduação em Psicologia foram fixados em 1963, voltados especificamente para a formação das pessoas cuja profissão foi regulamentada por aquela Lei, um ano antes. A história da consolidação da Psicologia no Brasil sofreu, em seu início, um impacto político com a implantação, em março de 1964, da ditadura civil-militar e interferências políticas na estruturação dos currículos de formação e campos de exercício prático.

Outra Lei, que criou o Conselho Federal e sete Conselhos Regionais de Psicologia, só foi promul- gada no final de 1971, quase dez anos depois da regulamentação da profissão. Esses Conselhos têm a função de orientar, disciplinar e fiscalizar o exercício profissional e servem ainda como tribunais de ética. Para exercer a profissão, o registro neles é obrigatório. Entretanto, bem antes já existiam algumas associações científicas e profissionais, que tiveram papel importante na regulamentação profissional e na fixação de normas para o ensino. A partir dessas considerações, o presente ensaio desenvolve algumas questões, oferece informações sobre como as pessoas são formadas e faz uma síntese crítica sobre a atuação profissional no Brasil.

\section{Profissão: o exercício que se amplia em distintos campos de trabalho}

Depois de um pouco mais de meio século, desde a regulamentação da profissão, há mais de $230 \mathrm{mil}$ profissionais inscritos nos atuais 23 Conselhos Regionais de Psicologia e mais de cinco mil instituições científicas e sindicais representando a área. Há hoje quase um Conselho Regional para cada estado brasileiro, o que é indicador relevante de crescimento e regionalização da profissão e ampliação da formação. Para acompanhar as transformações ocorridas desde 1962, um novo Código de Ética foi aprovado pelo Conselho Federal de Psicologia em 2005 e se constituiu como referência maior para o exercício profissional. Há 16 sindicatos de psicólogos, presentes em estados de todas as regiões brasileiras, mas não em todos os estados. A maioria desses sindicatos é filiada a uma federação nacional, criada no final de 1985, quando se encerrou formalmente a ditadura no Brasil. O exercício profissional acompanhou as movimentações políticas e econômicas, que alteraram suas características predominantes na década de 1960.

A partir da década de 1970 esses profissionais foram objeto de estudos sistemáticos de pesquisadores interessados nas relações entre o exercício de prática e as características de formação. Esse interesse passou por uma aceleração na década de 1990 e atingiu pouco mais de 900 textos divulgados até 2008 (Yamamoto \& Amorim, 2010). A maioria desses estudos é constituída por artigos científicos, 
teses de doutorado, dissertações de mestrado e monografias de conclusão de cursos. Demonstraram o movimento da Psicologia brasileira, suas dificuldades e perspectivas, segundo esses autores.

A presente seção recupera a síntese de uma pesquisa, cuja coleta de dados foi feita online, na primeira década de 2000. Embora um pouco antiga, esta pesquisa teve a vantagem de utilizar um questionário que já tinha sido aplicado na década de 1980. Isto possibilitou comparar dados através do tempo e chegar a alguns marcos relacionados ao desenvolvimento da profissão. A amostra, de conveniência e formada por voluntários, foi constituída por 4,196 participantes, todos com registro profissional nos Conselhos anteriormente citados (Bastos \& Gondim, 2010). O perfil da profissão, à época, revelou que mais de $80 \%$ eram do sexo feminino e jovens, com uma média de 37 anos de idade, formados há pouco mais de dez anosem cursos de nível de graduação que tem a duração mínima de cinco anos, nível exigido para o registro nos Conselhos Profissionais no Brasil.

Na década de 1980, vinte anos, portanto, após a regulamentação da profissão, havia uma concentração de $59 \%$ dos profissionais nas capitais dos estados brasileiros. No final da primeira década do presente século a situação estava invertida, com $52 \%$ em cidades que não eram capitais. Essa melhor distribuição no espaço nacional, também ocorreu quando foram comparadas as cinco grandes regiões geográficas do Brasil. Quase 75\% dos profissionais antes estavam concentrados na região Sudeste, que tem a grande maioria da população brasileira. Esta concentração foi reduzida para $60 \%$ quase trinta anos depois. $O$ número relativo de profissionais dobrou, no caso da região Sul (Bastos \& Gondim, 2010). Esse crescimento e as alterações na distribuição foram consequência de um momento de expansão dos Cursos de Graduação no país, sobretudo de Instituições de Ensino Superior (IES) privadas.

Alguns elementos nesse processo de desenvolvimento da profissão podem ser apontados, como por exemplo, as razões para a escolha da profissão, do campo de trabalho, remuneração e vínculo empregatício. A escolha da profissão, segundo os respondentes dessa pesquisa, foi fortemente guia- da por fatores internos (vocação, identificação, interesses) em contraposição a fatores externos (mercado, remuneração, status). Essa escolha teria sido aparentemente pouco influenciada por pessoas importantes, segundo os profissionais que responderam a pesquisa. No entanto, ao final dos seus cursos, ao escolherem a área de atuação, os fatores externos (oportunidades de mercado e remuneração) passaram a ter um peso mais elevado na escolha e decisão profissionais. Esse peso é pequeno, quando comparado ao peso dos fatores internos, mas difere entre as áreas de atuação escolhidas. O mercado de trabalho, por exemplo, é mais frequentemente relatado como importante pelos que escolhem a docência e a aplicação da Psicologia em organizações e trabalho. Entre os que escolhem a atuação em escolas e educação, o status social e a remuneração são os que menos pesam. Esta remuneração também é pouco importante entre os que escolhem a aplicação na área de saúde.

$\mathrm{O}$ ingresso no mercado de trabalho ocorre por meio de várias portas de entrada. Os recém-formados se inserem numa diversidade de contextos. A principal porta de entrada é o trabalho autônomo. Para esses ingressantes, o mercado de trabalho é restrito. Um terço deles não exerce a profissão para a qual foram formados, um quarto a exercem em paralelo com outras atividades.

Considerando o conjunto dos profissionais de Psicologia brasileiros (Bastos \& Gondim, 2010), só $35 \%$ atuam individualmente e a maioria o faz em equipes multiprofissionais. Seus grupos profissionais de afinidade são pessoas que atuam nas áreas da Saúde e em Ciências Humanas e Sociais. Há uma clara contra identidade, estabelecida com profissionais de Ciências Exatas. Os indicadores de centralidade do trabalho são quase tão elevados quanto os de centralidade da família, seguidos bem de longe pelos indicadores de centralidade do lazer. Esses profissionais descrevem o seu trabalho como promotor de humanização e de sociabilidade, impositor de normas e segurança e propiciador de realização. Gostariam que ele promovesse crescimento e independência, trouxesse reconhecimento econômico e propiciasse realização e igualitarismo. Quando comparadas as regiões brasileiras, no Sudeste estão 
Jairo Eduardo Borges-Andrade, Antonio Virgílio Bittencourt Bastos, Maria Amalia Pie Abib Andery, Raguel Souza Lobo Guzzo, Zeidi Araujo Trindade

os rendimentos mais elevados e no Nordeste estão os menores rendimentos, o que é compatível com as diferenças socioeconômicas entre essas regiões.

Dos participantes na pesquisa, todos inscritos nos Conselhos, a maioria (62\%) atua somente em Psicologia e há 22\% que a conciliam com outras atividades, provavelmente visando complementar suas rendas. Menos de 20\% desses inscritos trabalham exclusivamente fora do campo da Psicologia, podem já ter nele atuado e o abandonaram ou nunca nele atuaram. Os que nunca atuaram descrevem falta de oportunidades no mercado de trabalho, especialmente os que buscam a área clínica. Os motivos pessoais ou familiares foram descritos para justificar o abandono do trabalho em Psicologia. Os que atuam fora da Psicologia, mas ainda permanecem inscritos nos Conselhos, alegaram razões associadas à oferta de bons empregos e pretendem se inserir no campo profissional (Bastos \& Gondim, 2010).

É frequente, nessa amostra de pesquisa, a combinação de trabalhos com vínculos empregatícios assalariados e de natureza autônoma, especialmente entre os que só atuam em Psicologia. Os que são apenas assalariados representam aproximadamente um terço destes. A profissão tem, no Brasil, duas faces: uma de assalariados e outra de autônomos, sem grandes diferenças relativas a rendimentos mensais. Entre os assalariados, há $65 \%$ que combinam duas ou mais inserções profissionais. Eles estão em empregos públicos voltados para saúde, educação ou administração (40\%), no setor privado de ensino, de comércio, industrial ou de saúde (35\%) e no terceiro setor $(25 \%)$. Entre os autônomos, a maioria trabalha até vinte horas semanais, em locais alugados, e há proporções mais elevadas de recém-formados e de formados há mais de vinte anos. Metade dos autônomos tem atividades aplicadas em clínica, seguidos por $17 \%$ cujas atividades são aplicadas em organizações e trabalho e 16\% em saúde.

As ações dos profissionais de Psicologia, para $67 \%$ dos participantes, estavam concentradas em uma área de atuação, para 29\% em duas áreas e para 4\% em três áreas. A concentração em uma única área foi mais comum entre os que aplicam a Psicologia às organizações e ao trabalho (61\%), seguidos dos que a aplicam em clínica (51\%) e saúde (42\%). Entre a década de 1980 e a primeira década do presente século, ocorreu um aumento da atuação de profissionais na área da Saúde e uma redução da atuação em escolas, como consequência da política de ingresso na rede pública de Saúde e o fechamento das possibilidades de trabalho nas escolas públicas municipais e estaduais. Algumas atividades típicas do campo da clínica são realizadas em outras áreas de atuação, como escolar, saúde e organizações e trabalho. São uma manifestação explícita de que a formação não distingue os campos de atuação profissional e prepara para uma matriz clínica de atuação. Não ocorreram alterações substanciais na quantidade de profissionais que atuam nas áreas de clínica e de organizações e trabalho.

A clínica absorve um pouco mais da metade (51\%) do total de profissionais (em dedicação exclusiva ou em combinação com outras áreas), que atuam em espaços alugados e tem a pior remuneração mensal. A maioria (62\%) é constituída por autônomos e quase a metade só tem a formação no nível de graduação.

Menos de um terço dos profissionais atuam em saúde, em dedicação exclusiva ou em combinação com outras áreas. Os vínculos são predominantemente com organizações públicas, assalariados (82\%), ao contrário da área clínica. As remunerações mensais são bem maiores. Da mesma forma como na clínica, quase a metade dos participantes só tem formação no nível de graduação.

$\mathrm{Na}$ área de organizações e trabalho foram identificados $25 \%$ de profissionais, em dedicação exclusiva ou em combinação com outras áreas. Predominou o vínculo assalariado (48\%), principalmente com empresas privadas, seguido por atividades de consultoria autônoma. Os rendimentos mensais indicados foram ligeiramente mais elevados que na área de saúde. Tal como nas áreas anteriormente citadas, quase a metade dos respondentes só tem o curso de graduação.

Aproximadamente 10\% dos participantes da pesquisa atuam na área escolar, em dedicação exclusiva ou em combinação com outras áreas. Houve o predomínio do vínculo assalariado (69\%), com organizações privadas, mas, ainda muitos indicaram atuar como autônomos. Ao contrário das áreas de 
atuação anteriormente mencionadas, a maioria (54\%) já tem pós-graduação (especialização), mas menos de $10 \%$ têm mestrado ou doutorado.

Quase 15\% atuam, em dedicação exclusiva ou em combinação com as outras áreas, como docentes de cursos de nível superior, mais frequentemente em instituições privadas e depois em instituições públicas. Seus vínculos são assalariados, na grande maioria (85\%). Diferentemente de todas as outras áreas, 64\% são doutores e 33\% têm mestrado.

Os que indicaram ser mais afetivamente comprometidos com suas áreas de atuação foram os profissionais que atuam em docência de nível superior e os menos afetivamente comprometidos foram os da área escolar. Os mais instrumentalmente (ou calculativamente) comprometidos foram os que atuam na área jurídica e os escores mais baixos, nessa modalidade de comprometimento, foram daqueles que atuam em saúde (Bastos \& Gondim, 2010). Ainda segundo estes autores, este comprometimento segue uma racionalidade em que a continuidade do vínculo (com a área de atuação) está fundamentada no cálculo dos custos pessoais envolvidos, caso haja quebra desse vínculo. Por outro lado, aquele comprometimento tem uma base afetiva, fundamentada na identificação de objetivos e valores comuns e no desejo de exercer esforço em benefício do objeto do vínculo (a área de atuação).

A saúde ocupacional dos profissionais de Psicologia no Brasil parece ter indicadores razoáveis, ainda de acordo com a pesquisa mencionada. Os respondentes apresentaram satisfação geral com a vida (modo como são tratados, vida afetiva, relações com a família, realizações em toda a vida e trabalho atual). Os piores indicadores de satisfação foram relacionados com disponibilidade financeira, tempo de descanso e atividades de lazer. Predominaram afetos positivos. $O$ trabalho tendeu a promover a realização, com baixa despersonalização. Não apareceram indicadores elevados de exaustão emocional.

Em todas as áreas de aplicação da Psicologia, nesse estudo, foram mais frequentes as atividades de diagnóstico, seguidas pelas atividades de intervenção no nível individual. Atividades de caráter mais estratégico, visando mudanças de natureza geral, apareceram em terceiro lugar, relatadas pelos que exerciam a Psicologia em escolas, trabalho e saúde. As atividades de ensino foram predominantes no nível superior. A maioria dos profissionais (62\%) afirmou que utiliza mais de uma abordagem teórica para fundamentar suas atividades, segundo a pesquisa coordenada por Bastos e Gondim (2010). Dentre os que adotaram somente uma abordagem, houve predominância da psicanálise (18\%) e da abordagem cognitivo-comportamental (10\%).

Numa auto avaliação, os respondentes da pesquisa citada indicaram que suas competências de investigação científica e as competências para realizar diagnósticos de processos psicológicos em níveis acima dos individuais (grupais ou organizacionais) e para coordenar grupos estão pouco desenvolvidas. Por outro lado, opinaram que suas competências para avaliar problemas humanos em diversos contextos, para desenvolver vínculos profissionais, para realizar orientação, aconselhamento e psicoterapia e para trabalhar com profissionais de outras áreas estariam mais desenvolvidas. Para aprender no trabalho, utilizam estratégias intrínsecas combinadas com aplicação prática e busca de ajuda interpessoal. Mas recorreram, de maneira intensa, à aprendizagem decorrente de ações mais formais ou estruturadas.

Esses dados revelam que há uma busca contínua pelo aperfeiçoamento profissional decorrente dessas ações. Mais de 90\% dos respondentes da pesquisa citada relataram participações em eventos (congressos, reuniões, supervisão extra acadêmica, grupos de estudo). Mais de $80 \%$ frequentam cursos de curta duração. Esta formação complementar tem sido utilizada, independentemente do nível de titulação das pessoas. Aproximadamente $60 \%$ concluíram ou estavam cursando uma pós-graduação: especialização, na sua maioria; mestrado ou doutorado, em poucos casos. $\mathrm{O}$ investimento financeiro em qualificação atingia até 10\% dos rendimentos de $42 \%$ desses respondentes, entre 11 e $30 \%$ da renda de outros 39\% e mais que $31 \%$ de $11 \%$ deles.

A síntese dessa caracterização sobre a profissão no Brasil descreve um marco no desenvolvimento da Psicologia. Apresentou-se como um levantamento realizado após transformações substanciais 
Jairo Eduardo Borges-Andrade, Antonio Virgílio Bittencourt Bastos, Maria Amalia Pie Abib Andery, Raguel Souza Lobo Guzzo, Zeidi Araujo Trindade

na área, tais como o ingresso formal da profissão no serviço público, as reestruturações curriculares e de políticas educacionais decorrentes das mudanças políticas e econômicas vividas no país e que tiveram impacto na profissão. A seguir, serão apresentadas informações sobre a formação graduada e pós-graduada em Psicologia que é oferecida no Brasil.

\section{Formação básica: graduação em Psicologia}

A pesquisa anteriormente mencionada apresenta evidências de dissociação entre a formação básica e o exercício profissional em distintos campos de trabalho. A formação básica em Psicologia, que no Brasil credencia para o exercício profissional, tem a duração de cinco anos. É hoje regida por Diretrizes Curriculares Nacionais (DCN), fruto da mobilização de entidades profissionais e científicas de Psicologia e Instituições de Ensino Superior (IES) (CNE/CES, 2004). O processo de elaboração das DCN foi pautado pela necessidade de que a formação profissional básica levasse em conta as características da realidade brasileira. Novas demandas e desafios presentes no trabalho em distintos campos de atuação foram se abrindo para essa profissão, especialmente e mais recentemente, nos serviços públicos de Saúde, Assistência e Justiça.

Aliada à prática do psicólogo no Brasil, essa formação tem sido estudada por aqueles que acompanham seus mais relevantes momentos, desde quando foi reconhecida no país. Alguns desses estudos, ao longo do tempo, apontam para características que marcam a formação e seus principais dilemas, quando se leva em conta o tamanho do país, suas distintas características regionais e os compromissos necessários com as mudanças esperadas pelo perfil profissional formado nas IESs. (Botomé, 1988; Duran,1993; Achcar, 1994; Guzzo, 1996; Calais \& Pacheco, 2001; Marinho-Araújo \& Almeida, 2005; Cruces, 2006; Marinho-Araújo, 2007; Yamamoto \& Costa, 2010; Yamamoto, 2009; Azzi \& Gianfaldoni, 2011; Yamamoto, Falcão \& Seixas, 2011; Tizzei, 2014; Seixas, 2014). Além disso, a formação tem sido também discutida à luz do crescimento, expansão e privatização das IESs, fru- to de políticas nacionais e internacionais voltadas ao desenvolvimento econômico (Trindade, 2000; Gentili \& Alencar, 2001; Marinho-Araújo, 2007; Sguissardi, 2008; Severino, 2009; Morosini, 2011 \& Oliveira, 2011). Foi ainda objeto de um debate dentro do Conselho Federal de Psicologia, para o desenvolvimento de políticas de acompanhamento da formação profissional (Caniato, 2013).

Segundo o Ministério de Educação e Cultura (MEC, 2014), atualmente existem no Brasil 2.652 IESs, sendo a maioria (82\%) privadas. Em relação aos cursos de Psicologia, há uma sistematização feita por Seixas (2014), a partir de uma consulta a dados de domínio público, disponibilizados pelo cadastro de cursos de Psicologia no país no banco de dados do e-MEC. Essa sistematização demonstra o crescimento exponencial desde o primeiro curso no Brasil, com uma alta porcentagem de cursos em 2007, época em que as políticas educacionais ampliaram o acesso de jovens ao ensino superior. O primeiro pico de crescimento ocorreu na década de 1970. Mas o crescimento mais impressionante se deu a partir do final da década de 1990, com taxas que se aproximaram de 10\% anualmente.

Embora esse crescimento tenha ampliado o número de psicólogos formados em todo o país, a distribuição dos cursos ainda se mantem desigual, se forem consideradas as distintas regiões, com impacto no exercício profissional. Assim como no cenário mais geral dos cursos de graduação, o crescimento dos cursos de Psicologia acompanhou o movimento de privatização e concentração das instituições formadoras nas regiões sul e sudeste do país. Dados do MEC (2014) apontam que, das 642 IESs $^{1}$ que oferecem cursos de Psicologia, 550 são privadas. A região norte concentra 7\% dos cursos, a região nordeste $17 \%$, a região centro-oeste $7 \%$, a região sul $23 \%$ e a região sudeste $46 \%$.

O Instituto Nacional de Estudos e Pesquisas - INEP vem desenvolvendo e aperfeiçoando, continuamente, seus processos e instrumentos para tornar transparente à população os indicadores da qualidade da educação que lhe é oferecida, nos di-

1 Dados obtidos no site emec.gov.br. 
ferentes níveis de formação. Em 2012, na avaliação final dos Cursos de Psicologia, o Exame Nacional de Desempenho dos Estudantes (ENADE) envolveu a participação de 20.577 recém-egressos de 371 cursos avaliados. Os dados revelaram alguns elementos característicos do perfil que se mantém ao longo dos anos: $81 \%$ dos profissionais foram formados por IESs privadas, sendo $83 \%$ do sexo feminino e com a idade média de 29 anos.

Esse cenário e o revelado por outros estudos voltados à formação em Psicologia (Yamamoto, Oliveira \& Campos, 2002; Yamamoto, Souza, Silva \& Zanelli, 2010; Yamamoto, Seixas, Costa \& Coelho-Lima, 2013; Yamamoto, Falcão \& Seixas 2011; Lisboa \& Barbosa, 2009; Seixas, 2014; Baima, 2014; Tizzei, 2014) apontam para uma característica importante da formação básica em Psicologia, que não pode ser negligenciada na caracterização di profissional. Como ele é principalmente formado por instituições privadas, o impacto acontece de um modo mais característico na definição de seu perfil. Isto acontece porque IESs privadas tem restrições ao oferecimento de uma estrutura curricular diversificada e à oferta de um conjunto de disciplinas, estágios e oportunidades de aprofundamento em distintas ênfases. Entre estas oportunidades, estão as atividades de pesquisa. Sua restrição pode explicar a pouca competência em investigação científica, citada pelos participantes do estudo anteriormente sintetizado, em sua autoavaliação. $\mathrm{O}$ funcionamento de disciplinas nessas IESs, de um modo geral, está condicionado ao número de estudantes matriculados. Dessa forma, os programas são limitados e voltados ao perfil profissional com maior capacidade de absorção pelo mercado de trabalho. Isto obriga a que estudantes não possam, de fato, aprofundar sua formação em áreas ou abordagens de interesse individual. Essa limitação ainda afeta mais fortemente a efetiva realização de atividades de pesquisa, pois elas são custosas. É um círculo que não se rompe e que reproduz as características profissionais mais conservadoras, apesar do avanço das DCN em relação ao Currículo Mínimo fixado em 1963.

Levando-se em conta os estudos indicados anteriormente e o que pode ser concluído a partir deles, um ponto importante, ainda a considerar, é o perfil profissional definido nas DCN e os projetos pedagógicos curriculares (PPCs) formulados pelas IES, Por ser uma determinação do MEC para regulamentação dos cursos, os PPCs atendem às diretrizes, sem que a estrutura curricular implementada, de fato, ofereça condições pedagógicas de formação diferenciada. Muitas vezes não há estágios correspondentes ou um conjunto de disciplinas eletivas que complementem um perfil profissional para atender às demandas da realidade. Isso faz com que as possibilidades abertas pelas DCNs, para uma formação mais crítica, mais próxima aos problemas sociais da realidade brasileira, fiquem apenas expressas no papel.

As DCN foram estruturadas considerando importantes elementos para a formação básica: um conjunto de disciplinas instrumentais e de fundamentos; possibilidades de estágios diferenciados em níveis e distintos campos de atuação e ênfases curriculares que são oportunidades de aprofundamento de estudo e atuação. As ênfases não especializam, mas são possibilidades curriculares que oferecem um campo de interesse aos estudantes, sobretudo, quando há uma relação estreita com os Programas de Pós-graduação (PPGs). A relação Pós-Graduação e Graduação se materializa nas possibilidades de ênfase - pela oportunização da pesquisa, do conhecimento novo, aprofundamento de estudos e experiências de atuação diferenciadas. Contudo, o número de cursos de graduação é exponencialmente maior do que os programas de pós-graduação. Portanto, as ênfases curriculares, na maioria dos cursos básicos, acabam sendo definidas sem a pesquisa na área. Concentram-se nos campos de trabalho mais voltados para a Saúde. Constituemse novamente em uma estrutura conservadora que marca o perfil do psicólogo brasileiro.

De um lado, a formação básica do profissional de Psicologia se dá, majoritariamente, nas IESs privadas. Entretanto, a Pós-Graduação Stricto-Sensu se distribui, em número muito menor, quase que exclusivamente nas instituições públicas, conforme indicado na próxima seção. $O$ crescimento de cursos de Graduação no Brasil, nos últimos dez anos, pela via das IES privadas, mudou de forma intensa o número 
Jairo Eduardo Borges-Andrade, Antonio Virgílio Bittencourt Bastos, Maria Amalia Pie Abib Andery, Raguel Souza Lobo Guzzo, Zeidi Araujo Trindade

de profissionais buscando trabalho e acentuou as dificuldades na formação. Com isso, alguns nexos são necessários para que a avaliação da profissão possa resultar em um quadro mais favorável. Um dos pontos importantes é a relação da Graduação com a Pós-Graduação, em que indicadores de integração deveriam ser mais contundentes, no sentido de produção e visibilidade dos estudos voltados à realidade brasileira e formação mais intensa para o ensino da Psicologia na graduação.

\section{Formação pós-graduada em Psicologia}

Refletir sobre a formação e a avaliação da pós-graduação no Brasil implica delimitar a análise à pósgraduação stricto sensu (mestrados e doutorados). A oferta de cursos lato sensu (especializações com duração acima de 360 hs.) não está restrita às IESs e não é acompanhada por avaliações sistemáticas. Por outro lado, os cursos stricto sensu "tornaram-se alvo de regulamentações cada vez mais detalhadas, com critérios rigorosos e avaliações periódicas, ganhando uma configuração que os limita às instituições de ensino e pesquisa" (Menandro, Tourinho, Bastos \& Yamamoto, 2013, pp. 189-190). Como consequência, para análise dos cursos lato sensu há, nesse momento, falta de dados confiáveis que permitam ponderações sobre a qualidade da formação oferecida, embora se reconheça sua importância.

A Pós-Graduação brasileira, muito especialmente a stricto sensu, tem sido orientada pelos Planos Nacionais de Pós-Graduação (PNPG) desde 1975, que buscam implantar diretrizes estratégicas para atingir metas importantes para o país na sua busca por desenvolvimento econômico e social. Essa implantação é responsabilidade da Fundação Coordenação de Aperfeiçoamento de Pessoal de Nível Superior (CAPES) ${ }^{2}$. Há mais de 5.300 Programas de Pós-Graduação (PPG), distribuídos em 48 áreas de atuação/avaliação, cada uma sendo representada por um docente nomeado pela presidência da CAPES, com participação inicial da

2 Agência governamental vinculada ao Ministério da Educação que tem como função principal a implantação, gestão e avaliação do Sistema de Pós-Graduação stricto sensu brasileiro. comunidade acadêmica daquela área Uma dessas áreas é a Psicologia.

Os PPGs eram avaliados trienalmente, por pares da área e depois por representantes de todas as áreas. $\mathrm{O}$ formato permanece o mesmo, mas a partir de 2014 a avaliação passou a ser realizada em quadriênios. A CAPES institui normas e critérios para a implantação e avaliação dos PPGs stricto sensu brasileiros, definindo um padrão de avaliação constituído por cinco quesitos: Proposta do PPG, Corpo Docente, Corpo Discente, Produção Bibliográfica e Inserção Social. Todos os quesitos são subdivididos em diferentes itens, estes com flexibilidade para atender as especificidades das diferentes Áreas. Com base nesses quesitos são atribuídas notas globais, que variam de três a sete. Os que não alcançam a nota três são automaticamente descredenciados do sistema. Como novidade implantada no último triênio, cada área faz Seminários Anuais de Acompanhamento, nos quais representantes dos PPGs se reúnem com a coordenação de Área para discutir o desempenho dos PPGs, questões táticas e estratégicas da área e suas especificidades.

O sistema de pós-graduação stricto sensu na área de Psicologia compreendia, até 2012, 73 PPGs, considerando-se as propostas de novos cursos aprovadas ao longo do ano e que foram implantadas em 2013. Como revela a Figura 1 houve crescimento contínuo do número de cursos ao longo dos últimos anos. Em relação aos 28 cursos de mestrado e aos 16 cursos de doutorado existentes em 1998, os números alcançados em 2012 representam um crescimento de $161 \%$ no número de PPGs (e de mestrados) e de 194\% no número de doutorados. O crescimento de cursos de mestrado, menos intenso nos anos 2008, 2009 e 2010, foi retomado nos anos de 2011 e 2012.

O crescimento da área de Psicologia acompanhou o crescimento geral do sistema de pós-graduação brasileiro, não se alterando significativamente a participação da área no conjunto da pós-graduação no país. Pode parecer um crescimento grande, mas foi pequeno, quando comparado ao crescimento dos cursos de Graduação, mencionado na seção anterior. Em 2012, a área de Psicologia representava $2 \%$ dos 5,328 cursos de pós-graduação do país e 16\% dos cursos vinculados à Área das Ciências 
Humanas. Com 73 PPGs, a Psicologia ocupa nas Ciências Humanas a segunda posição, abaixo apenas da Área de Educação.

Ainda antes de ocorrer esse crescimento expressivo dos cursos de pós-graduação, foi criada uma associação nacional de PPGs em Psicologia, em 1983. Seus objetivos envolvem o aperfeiçoamento da formação pós-graduada e da pesquisa científica e só existem membros institucionais. Ela promove encontros bienais de pesquisadores vinculados àqueles PPGs. Por outro lado, há uma associação brasileira que congrega pessoas interessadas na pesquisa em todas as áreas da Psicologia, criada em 1991. Tem um periódico científico e realiza um congresso científico anual. Ela é sucessora de uma entidade científica local fundada em 1971 e sua missão é voltada ao desenvolvimento cientifico e técnico e à defesa dos responsáveis por esse desenvolvimento. Existem ainda quase duas dezenas de entidades científicas similares a esta última, todas de caráter nacional, mas com o foco em áreas específicas como avaliação, desenvolvimento, escolar, esporte, hos- pitalar, medidas de personalidade, neuropsicologia, psicoterapia, organizações e trabalho, orientação profissional, política, psicoterapia, saúde e social. Muitas dessas entidades realizam regularmente eventos científicos e mantêm periódicos científicos especializados.

Metade dos PPGs em Psicologia encontra-se no Sudeste brasileiro (27\% apenas no Estado de São Paulo) (Tabela 1). Tal distribuição reflete o que igualmente ocorre no sistema nacional de pós-graduação. Também a exemplo do que ocorre neste sistema, a maioria (quase 70\%) dos PPGs em Psicologia se insere em IESs públicas (federais e estaduais).

Em 2012 foram identificadas 229 linhas de pesquisa ativas nos mais de 70 PPGs em Psicologia, incluídas em diferentes subáreas (Figura 2). Nos casos em que as linhas de pesquisa envolviam interfaces claras entre duas subáreas, as linhas foram também categorizadas em uma segunda subárea. Ao todo, as linhas de pesquisa existentes geraram, então, 277 categorizações. Três subáreas concentram $43 \%$ das

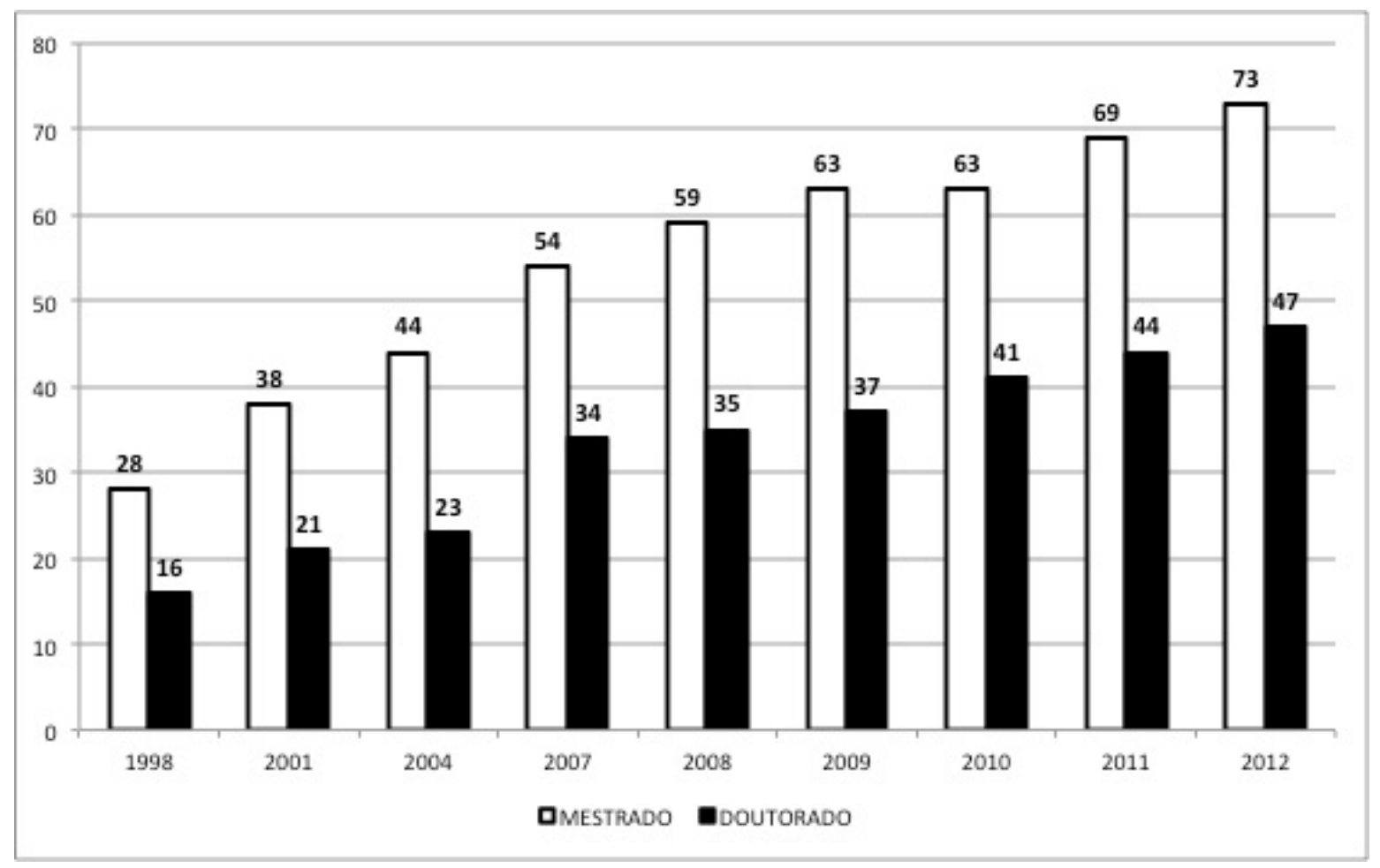

Figura 1. Número de cursos de Mestrado e Doutorado em Psicologia, desde 1998

Fonte: elaboração própria 
linhas de pesquisa: Social, Clínica e Processos Básicos. Somando-se as subáreas de Desenvolvimento e da Saúde, as cinco subáreas concentram $62 \%$ das linhas de pesquisa. Um conjunto expressivo de 21 linhas (8\%) foi incluído em uma categoria denominada "gerais/temas transversais". Essas linhas mantêm estreita interface com a Psicologia Social ou a Psicologia Clínica, articulando a noção de processos de subjetivação, constituição do sujeito ou construção da subjetividade aos contextos culturais, sociais, políticos e contemporaneidade. Outras subáreas estão sub-representadas.

A análise das linhas de pesquisa sugere interfaces estreitas com outras áreas, na produção de conhecimento e no exercício profissional. Tais interfaces envolvem o campo das ciências biológicas (por exemplo, psicobiologia, psicofarmacologia, psicologia evolucionista, etologia e neurociências). Têm pontos de ligação com as ciências humanas e sociais (antropologia, sociologia, história) em temáticas como violência ou em campos como o cultural ou comunitário. Articulam-se de diversas formas com a área da saúde (mental, do trabalhador, hospitalar, gerontologia, adesão a tratamentos, dependências químicas, dor). Conectam-se com todo o espectro das ciências sociais aplicadas (organizações, trabalho, educação, comunicação, trânsito, economia, direito) e alcançam os domínios da literatura, da linguística, das artes e do universo da informática. Há campos de pesquisa reconhecidos e com tradição construída, como é o caso da Psicologia Ambiental, que tem interlocução importante com a Geografia, a Arquitetura e Urbanismo e a Ecologia.
O total de Mestres e Doutores formados permite verificar se o aumento no número de PPGs tem correspondência com o aumento de profissionais titulados em Psicologia. Tomando 1996 como ponto de partida (Figura 3), o número de mestres titulados saltou de 296 para 1.131 em 2011, um crescimento de $282 \%$. No caso dos doutores, este salto foi de $443 \%$. São taxas expressivas de expansão de concluintes dos PPGs em 16 anos. Neste período, foram titulados 11.942 mestres e 3.171 doutores. Esta é uma contribuição significativa para a qualificação do corpo docente dos cursos de graduação e, em certa medida, com a preparação de recursos humanos mais qualificados para o mundo do trabalho.

Para fomentar a qualidade da formação oferecida, a CAPES oferece bolsas aos estudantes dos PPGs em Psicologia no Brasil. Desde 2004, ocorreu um crescimento de $117 \%$ no número total de bolsas, que saltou de 756 para 1639 em 2012. Há também apoio da CAPES à internacionalização, com a concessão de bolsas no exterior (doutorados sanduiches e doutorados plenos para estudantes e, para docentes, estágios sênior e pós-doutoral). Visam criar oportunidades para o desenvolvimento de parcerias de pesquisa, entre docentes, e de complementação da formação em centros de excelência em outros países, para os discentes. Do total de bolsas concedidas até 2012, 68\% foram bolsas de doutorado-sanduiche (3 a 12 meses). Esta modalidade foi e continua sendo a mais fortemente apoiada ao longo da última década. Por meio dela, os estudantes matriculados em cursos de doutorado no Brasil realizam atividades em cursos de

TABEla 1.

Distribuição dos PPGs em Psicologia por regiões do Brasil em 2012

\begin{tabular}{lcccc}
\hline \multirow{2}{*}{ Regiões do país } & \multirow{2}{*}{ PPGs } & \multicolumn{3}{c}{ Cursos } \\
\cline { 3 - 5 } & & Doutorado & Mestrado (Acadêmico) & Mestrado Profissional \\
\hline Norte & $4(5.5 \%)$ & $1(2.1 \%)$ & $4(5.6 \%)$ & 0 \\
Nordeste & $13(17.8 \%)$ & $8(17.0 \%)$ & $13(18.3 \%)$ & 0 \\
Sudeste & $37(50.7 \%)$ & $26(55.3 \%)$ & $35(49.3 \%)$ & $2(100 \%)$ \\
Sul & $10(13.7 \%)$ & $5(10.6 \%)$ & $10(14.1 \%)$ & 0 \\
Centro-oeste & $9(12.3 \%)$ & $7(14.9 \%)$ & $9(12.7 \%)$ & 0 \\
TOTAL & 73 & 47 & 71 & 2 \\
\hline
\end{tabular}

Fonte: elaboração própria 


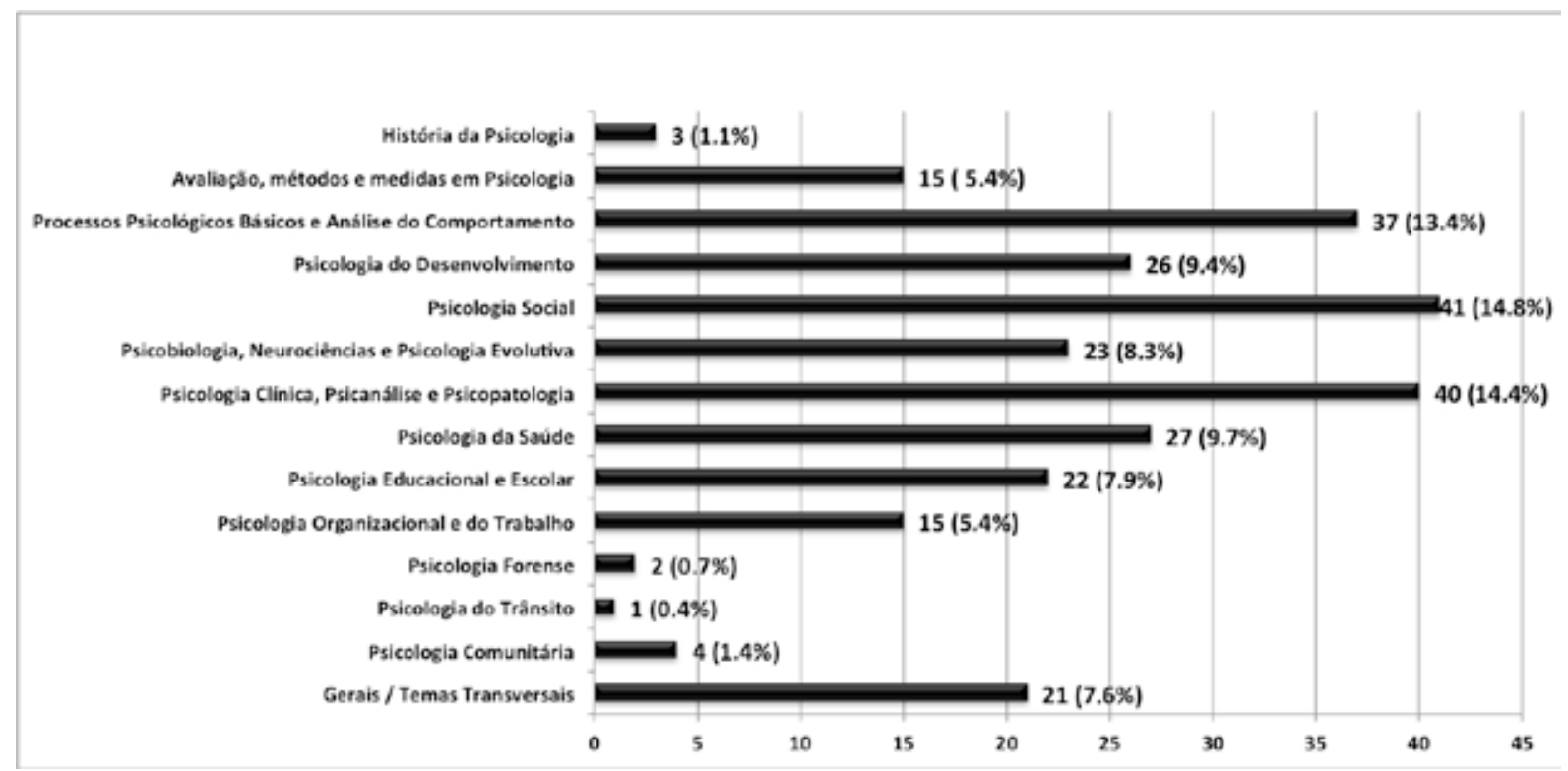

Figura 2. Distribuição das linhas de pesquisa dos PPGs em Psicologia em 2012

Fonte: elaboração própria

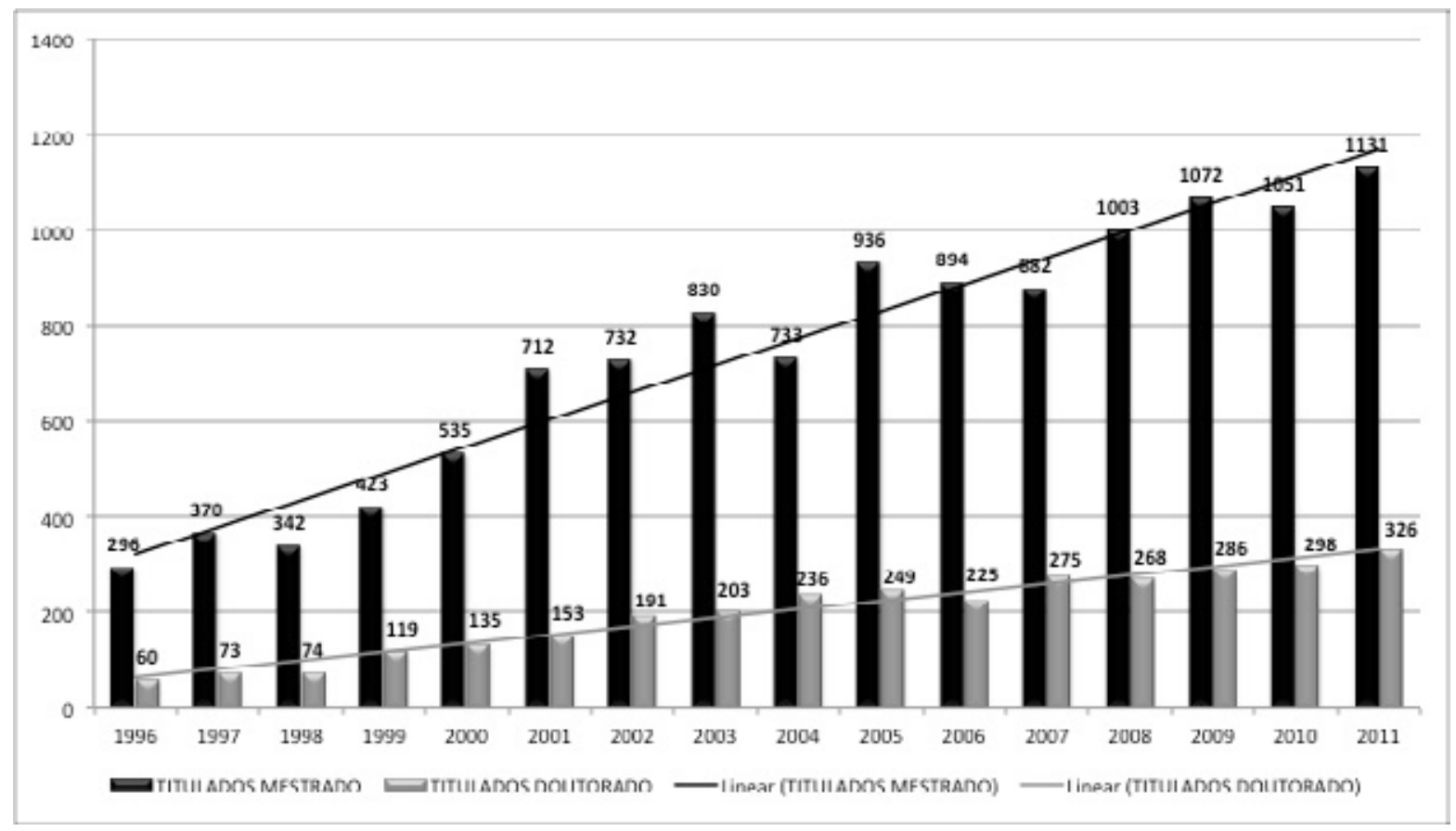

Figura 3. Evolução do número de mestres e doutores titulados em Psicologia (1998-2011)

Fonte: elaboração própria

doutorado no exterior, sob orientação de docentes destes, geralmente entre o segundo e terceiro anos do curso.
Na avaliação da produção intelectual, são considerados os artigos em periódicos científicos, livros e capítulos de livros publicados nos PPGs de 
Jairo Eduardo Borges-Andrade, Antonio Virgílio Bittencourt Bastos, Maria Amalia Pie Abib Andery, Raguel Souza Lobo Guzzo, Zeidi Araujo Trindade

Psicologia pelos seus discentes, egressos (até três anos depois de titulados) e docentes permanentes. Periódicos são classificados de acordo com uma escala de sete pontos e livros em uma escala de quatro pontos. Para cada publicação informada atribui-se pontuação de acordo com tais escalas. Na última avaliação trienal (realizada com base nos desempenhos dos PPGs de Psicologia entre 2010 e 2012) foram informados e avaliados 11.764 itens. Destes, 7.373 foram artigos publicados em periódicos científicos (um aumento de $53 \%$ em relação ao triênio anterior). Sua produção representa uma média de 2.5 artigos por docente permanente/ano. Esse escore médio de produção de artigos esconde uma grande variabilidade. A produção de artigos levou a um crescimento e melhoria de qualificação dos periódicos científicos. Um dos resultados desse crescimento e da política de avaliação desses periódicos foi o surgimento de uma associação brasileira de editores científicos de Psicologia, cuja missão é promover a qualidade e visibilidade dessa produção intelectual.

O perfil da produção também se diversifica quanto ao peso de artigos e de livros/capítulos na produção total dos PPGs. No geral, 62\% dos itens produzidos no triênio são de artigos, indicando um crescimento da proporção desse tipo de produção sobre o total de itens publicados, comparativamente com o triênio anterior (59\%). A proporção de livros e capítulos corresponde a 38\% da produção total de itens da Psicologia. Contudo, há grande variabilidade entre PPGs.

O processo de avaliação se concretiza sobre uma realidade que é dinâmica e influenciada pelo próprio sistema de avaliação. Uma das dimensões de tal dinâmica revela-se no afastamento de docentes que foram os criadores de muitos PPGs e a consequente renovação do corpo docente. Tal processo de renovação tem implicações sobre os indicadores de produção e afeta as próprias definições de linhas de pesquisa e áreas de concentração. De maneira semelhante, diretrizes do PNPG 2011-2020, com a ênfase sobre a produção, o impacto sobre a realidade social e a internacionalização, se expressam em novos modelos de articulação de grupos de pesquisadores, construção de redes e parcerias entre docentes e PPGs, que se traduzem em índices crescentes de produção bibliográfica. Tais movimentos mostram a necessidade de atenção cuidadosa aos critérios, indicadores e métricas utilizadas no processo de avaliação.

\section{Desafios e dificuldades}

O campo profissional da Psicologia brasileira passou por grandes transformações, mas há aspectos inalterados e isto não é necessariamente desejável. Por outro lado, ocorreram mudanças para pior, como o aumento da precariedade do trabalho profissional. Há indicadores de fragilidade desse mercado de trabalho. Houve expansão do campo de trabalho da profissão e ampliação do seu leque de serviços, dos contextos em que a Psicologia é aplicada e dos segmentos da população que são beneficiários. Mas ocorreu perda de espaço na área de educação.

É frequente a diversificação de áreas de atuação profissional, mas ela é muitas vezes uma consequência da necessidade de criar mais inserções para complementar rendimento. A adoção de múltiplos referenciais teóricos pode produzir confusão e fragilizar os fundamentos que deveriam orientar o trabalho dos que atuam em Psicologia. Há algumas discrepâncias grandes entre competências necessárias e adquiridas, que sugerem problemas concernentes à formação profissional. Essas discrepâncias podem sinalizar o que precisa ser alterado, na graduação, e o que precisa ser oferecido na pós-graduação. As linhas de pesquisa dos PPGs, além disto, poderiam ser mais voltadas para investigar as práticas profissionais da Psicologia.

O número de profissionais de Psicologia cresceu substancialmente, em decorrência do crescimento vertiginoso dos cursos. A formação básica é majoritariamente oferecida pelas IESs privadas e esta característica foi acentuada nos últimos vinte anos. A formação pós-graduada também cresceu expressivamente, mas foi incapaz de acompanhar as demandas vindas do ensino de graduação e do mercado de trabalho. Mesmo assim, há um número grande de titulados, no nível de mestrado, trabalhando nas IESs privadas, enquanto nas públicas há um número maior de doutores. A formação 
pós-graduada é principalmente oferecida pelas IESs públicas e é submetida a um processo de avaliação bastante cuidadoso. A qualidade da formação, com exceções, é superior no segmento minoritário destas IESs.

Alguns desafios estão claramente colocados para a formação, no nível da graduação e da pós-graduação. No primeiro caso, o desafio que se impõe é tornar as experiências curriculares efetivamente correspondentes aos projetos pedagógicos apresentados pelas IESs. Para isto, é necessária uma avaliação mais contundente dos cursos de graduação, que exija distintas ênfases e uma inserção social consequenteem cada região brasileira.

Na pós-graduação, ocorreram avanços em termos de distribuição geográfica, nas regiões norte e centro-oeste. No entanto, ainda há cinco estados sem curso de pós-graduação stricto sensu em Psicologia. Uma melhoria nessa distribuição precisa preservar os padrões de qualidade do sistema, por meio de acompanhamento intensivo e de criação de redes de parcerias com PPGs consolidados. Será preciso diminuir a assimetria entre subáreas contempladas nas linhas de pesquisas ativas. Há campos de aplicação importantes, com grande potencial de inserção, praticamente ausentes (por exemplo, Psicologia Ambiental e do Esporte) ou com presença mínima na pós-graduação (por exemplo, Psicologia do Trânsito e Forense). Por outro lado, há cinco subáreas que concentram quase $2 / 3$ das linhas de pesquisa. Essas desigualdades precisariam ser reduzidas. Há ainda desigualdades entre os PPGs na distribuição de bolsas oferecidas pelas agências governamentais.

A Psicologia terá que avançar na oferta de mestrados profissionais, além dos acadêmicos, que estão bem consolidados. Isto exige a formação de parcerias com o setor extra-acadêmico, para qualificação de pessoas para o mercado de trabalho, especialmente no caso de políticas públicas de saúde e educação. O campo profissional poderia ser transformado num locus especial para investigação e desenvolvimento de tecnologias indispensáveis à melhoria dos serviços que os psicólogos prestam à sociedade.

A missão de formar pessoas para atuar, ensinar e pesquisar, em contextos regionais e locais múltiplos, em subáreas com singularidades muito claras, torna o processo de avaliação um desafio permanente. É importante assegurar clareza e precisão dos indicadores utilizados, assim como procedimentos que garantam a equanimidade e a ética dos procedimentos avaliativos. Há necessidade de contemplar parâmetros unificados, ao mesmo tempo que se busca respeitar singularidades e a diversidade interna, que deve ser valorizada.

A Psicologia ainda não apresentou uma proposta de como, no seu conjunto e de forma mais abrangente, poderá se inserir no esforço coletivo para melhorar a qualidade da formação nos diferentes níveis de ensino brasileiros. Este sistema educacional é um só com distintas etapas, cada qual com suas características e demandas. Por essa razão, a mais desafiadora das perspectivas é integrar as duas pontas do sistema e todas as suas etapas. A integração e a qualificação dessas pontas, e do que há entre elas, deveriam ser as metas buscadas para a próxima década.

\section{Referências}

Achcar, R. (1994). Introdução. Em R. Achcar (Org.) Psicólogo brasileiro - práticas emergentes e desafios para a formação (pp.1-6). São Paulo: Casa do Psicólogo/CFP.

Azzi, R. G., \& Gianfaldoni, M. H. T. A. (2011). Psicologia e Educação. São Paulo: Casa do Psicólogo.

Baima, L. S. (2014). Limites e possibilidades na contribuição para a mudança social: uma avaliação da formação em Psicologia Social Comunitária no Brasil. Dissertação de Mestrado inédito. Pontifícia Universidade Católica de Campinas.

Baptista, M. T. D. S. (2010). A regulamentação da profissão psicologia: documentos que explicitam o processo histórico. Psicologia: Ciência e Profissão, 30 (número especial), 170-191.

Bastos, A. V. B., \& Gondim, S. M. G. (Orgs.) (2010). O trabalho do psicólogo no Brasil. Porto Alegre: Artmed.

Botomé, S. P. (1988). Em busca de perspectivas para a Psicologia como área de conhecimento e como campo profissional. Em Conselho Federal de Psi- 
cologia (Org.). Quem é o psicólogo brasileiro? (pp. 273-297) São Paulo: CFP.

Calais, S. L., \& Pacheco, E. M. C. (2001). Formação de psicólogos: análise curricular. Psicologia Escolar e Educacional, 5(1), 11.

Caniato, A. (2013). A Formação de Psicólogas e Psicólogos: respondendo às demandas da sociedade brasileira. Texto elaborado a partir da oficina Formação de Psicólogos organizada pelo CFP. Brasília: CFP Grupo de Trabalho sobre Formação.

Conselho Nacional de Educação CNE/CES ( 2004, 18 de maio). Diretrizes Curriculares de Psicologia. Resolução 8/2004. Diário Oficial da União, Brasília, Seção 1, pp. 16-17.

Cruces, A. V. V. (2006). Egressos de Psicologia: preferências, especializações, oportunidades de trabalho e atuação na área educacional. Tese de Doutorado inédito. Programa de Pós Graduação em Psicologia, USP - Universidade de São Paulo, Brazil..

Duran, A. (1993). Interação Social: o social, o cultural e o psicológico. Temas em Psicologia, 1(3), 1-8.

Gentili, P. \& Alencar, C. (2001). Educar na Esperança em Tempos de Desencanto. Petrópolis: Ed. Vozes.

Guzzo, R. S. L. (1996). Formando psicólogos Escolares no Brasil: dificuldades e perspectivas. Em Wechsler, S. M. (Org.). Psicologia Escolar: pesquisa, formação e prática (pp.75-92) Campinas: Alínea.

LLisboa, F. S. \& Barbosa, A. J. G. (2009). Formação em Psicologia no Brasil: Um Perfil dos Cursos de Graduação. Psicologia Ciência e Profissão, 29 (4), 718-737.

Marinho-Araújo, C. M. (2007). A Psicologia escolar nas diretrizes curriculares: espaços criados, desafios instalados. Em Campos, H. R. (Org.). Formação em Psicologia Escolar: realidades e perspectivas (pp. 17-48.). Campinas: Ed. Alínea.

Marinho-Araújo, C. M., \& Almeida, S. F. C. de (2005). Psicologia Escolar: Construção e Consolidação da Identidade Profissional. Campinas: Ed.

Brasil, Ministério da Educação (2014). Instituições de Educação Superior e Cursos Cadastrados. Site: http://emec.mec.gov.br/ (informação obtida em 18 de maio de 2015.

Menandro, P. R. M., Tourinho, E. Z., Bastos, A. V. B., \& Yamamoto, O. H. (2013). Graduate and undergra- duate studies: neighbors without affinity? Paidéia, 23(55), 187-196.

Morosini, M. C. (Org.). (2011). A Universidade no Brasil: concepções e modelos. Brasília, DF: INEP.

Oliveira, C. B. E. de. (2011). A Atuação da Psicologia Escolar no Ensino Superior: proposta para os serviços de Psicologia. Tese de doutorado inédito. Programa de Pós Graduação em Psicologia, UnB. Brasília.

Seixas, P. de S. (2014). A Formação Graduada em Psicologia no Brasil: reflexão sobre os principais dilemas em um contexto Pós-DCN. Tese de doutorado inédito. Programa de Pós Graduação do Centro de Ciências Humanas, Letras e Artes, UFRN, Fortaleza.

Severino, A. J. (2009). Expansão do Ensino Superior: contextos, desafios, possibilidades. Avaliação, 14(2), 253-266.

Sguissardi, V. (2008). Modelo de expansão da Educação Superior no Brasil: predomínio privado/mercantil e desafios para a regulação e a formação universitária. Educação e Sociedade, 29, 991-1022.

Soares, A. R. (2010). A psicologia no Brasil. Psicologia: Ciência e Profissão, 30(número especial), 8-41.

Tizzei, R. P. (2014). Formação em Psicologia Escolar: perspectiva crítica na ênfase para o campo educativo. Tese de doutorado inédito. Programa de Pós Graduação, PUC Campinas. Campinas.

Trindade, H. (org.) Universidade em ruínas na república de professores. 2. ed. Petrópolis: Vozes/Rio Grande do Sul: CIPEDES, 2000.

Yamamoto, O. (2009). Formação em Psicologia e as Novas Demandas Sociais: relato dos egressos da Universidade de Fortaleza. Revista Mal-Estar e Subjetividade, IX(3), 1023-1042.

Yamamoto, O. H., \& Amorim, K. M. O. (2010). Estudando a profissão de psicólogo no Brasil: introdução. Em O. H. Yamamoto \& A. L. F. Costa (Orgs.). Escritos sobre a profissão de psicólogo no Brasil (pp. 17-31). Natal: EDUFRN.

Yamamoto, O. H., \& Costa, A. L. F. (Orgs.) (2010). Escritos sobre a Profissão de Psicólogo no Brasil. Natal, RN: EDUFRN.

Yamamoto, O. H., Falcão, J. T. da R., \& Seixas, P. de S. (2011). Quem é o estudante de Psicologia no Brasil? Avaliação Psicológica, 10(3), 209-232.

Yamamoto, O. H., Oliveira, I. F., \& Campos, H. R. (2002). Demandas Sociais Formação Profissional 
em Psicologia. Revista do Departamento de Psicologia (UFF), 14(1), 75-86.

Yamamoto, O. H., Seixas, P. S., Costa, A. L. F., \& Coelho-Lima, F. (2013). The role of Social Psychology in Brazilian undergraduate and graduate education. Estudos de Psicologia (UFRN), 18, 83-92.
Yamamoto, O. H., Souza, J. A. J., Silva, N., \& Zanelli, J.C. (2010). A formação básica, pós-graduada e complementar do psicólogo no Brasil. Em Bittencourt, A. V., \& Guedes, S. M. (Orgs.). O trabalho do psicólogo no Brasil (pp. 45-65). Porto Alegre: Artmed/Bookman. 
